\title{
Erratum to: A new mutation in the menin gene causes the multiple endocrine neoplasia type 1 syndrome with adrenocortical carcinoma
}

\author{
M. Haase • M. Anlauf • M. Schott •
}

S. Schinner · E. Kaminsky $\cdot$ W. A. Scherbaum •

Holger S. Willenberg

Published online: 12 April 2011

(C) Springer Science+Business Media, LLC 2011

Erratum to: Endocr (2011) 39(2):153-159

DOI 10.1007/s12020-010-9424-3

In the original publication, the name of the mutation c. $1327 \mathrm{C}>\mathrm{A}$ is incorrect. The correct name is c.1328C $>\mathrm{A}$.

The online version of the original article can be found under doi:10.1007/s12020-010-9424-3.

M. Haase - M. Schott - S. Schinner - W. A. Scherbaum ·

H. S. Willenberg $(\bowtie)$

Department of Endocrinology, Diabetes and Rheumatology,

University Hospital Duesseldorf, Moorenstr. 5, 40225

Duesseldorf, Germany

e-mail: Holger.Willenberg@uni-duesseldorf.de

M. Anlauf

Department of Pathology, University Hospital Duesseldorf,

Duesseldorf, Germany

E. Kaminsky

Praxis für Humangenetik-Altona, Hamburg, Germany 